\title{
Challenges and Responsibilities Facing Canadian Literacy Researchers Working in Global Communities
}

\author{
MARLENE ASSELIN \\ University of British Columbia \\ RAY DOIRON \\ University of Prince Edward Island \\ JON SHAPIRO \\ University of British Columbia
}

\section{Abstract}

This article addresses issues facing Canadian literacy researchers who are working in global contexts and particularly the potential complications that arise when research conducted in developing countries is funded by sources such as international aid institutions, foreign governments, non-governmental organizations, and donor-based organizations. We focus especially on the issue of development of local research capacity and expansion of the knowledge economy. We first create a framework by describing the types of literacy projects funded by alternatives to the standard research grants of government agencies. We next review tensions that can arise between researchers and these types of funding organizations. We then turn to examples of current Canadian literacy research carried out in developing countries that provide guidance in designing, conducting, and publishing locally-empowering and globallyconnected research.

Canadian literacy scholars are part of a growing number of Western academics engaged in literacy research in "developing countries." Increasingly, this work is premised on research as a means of social change (e.g., Kendrick \& Hissani, 2007; Kendrick \& Jones, 2008; Metcalfe, Esseh \& Willinsky, 2009; Mitchell, Moletsane, Stuart, Buthelezi, \& de Lange, 2008; Mutonyi \& Kendrick, in press; Norton \& Mutonyi, 2010; Oates, 2009; Tembe \& Norton, 2008), with Canadian examples including work with local researchers to create community-development projects with a research focus on local languages (Tembe \& Norton, 2008), literacy in warravaged communities (Oates, 2009) and HIV/AIDS education (Mutonyi \& Kendrick, in press).

Given limited financial and technological resources in "developing countries," much of the literacy research conducted in these locations is funded by outside sources, including international aid institutions (e.g., World Bank); foreign governments (e.g., Canadian International Development Agency (CIDA); and non-governmental organizations (NGOs) and donor-based organizations (e.g., RGK Foundation, Ford Foundation). For Canadian and other researchers from "developed countries," such funding sources are alternatives to traditional grants (e.g., SSHRC and university) and may provoke new ethical considerations in how 
research is conducted, disseminated and used. In this article, we use the term "alternative sources" to refer to funding from any of the above types of organizations.

As recognized in the 2nd Tri-Council Policy Statement of Research with Humans (Canadian Institutes of Health Research, Natural Sciences and Engineering Research Council of Canada, and Social Sciences and Humanities Research Council of Canada, 2010), research conducted by Canadian scholars that involves international and Aboriginal communities requires special measures to ensure adherence to the core principles of human dignity: respect for persons, concern for welfare, and justice. Regardless of the source of funding - be that grants, contracts, "traditional" or "alternative" sources - Canadian researchers are guided by the principles and articles in the Tri-Council policy. However, we argue that additional challenges and considerations come into play when research carried out in "developing countries" is funded by alternative sources such as those listed above. In such situations, relationships between the cultures of the Academy and these alternative funders can be marked with tensions and dilemmas about research purposes, theoretical perspectives, research designs, ethical procedures and researcher roles (Choudry, 2007; Cranshaw, 1985; Fetterman, 1984; Luke, 2003; Maclure, 2006; Samoff, 1996; Wickens \& Sandlin, 2007). These are pressing matters to be addressed by Canadian literacy scholars in light of the growing understanding of the role of researchers in perpetuating intellectual dependency in countries entering the global knowledge economy. It is not our intent to compare challenges and considerations of research funded by traditional sources and alternatives to the standard research grants of government agencies, but to extend the discussion on research ethics into these funding situations, particularly donor-controlled research. This article was inspired by our personal experiences as literacy researchers working with donor-based organizations in different capacities - one of us as a member of the Board of the Directors of such an organization, and the other two as collaborators in research projects with non-governmental organizations in Canada and East Africa.

The paper attempts to raise awareness about the multiple issues facing Canadian literacy researchers who are working in global contexts and particularly the potential complications arising when research is funded by alternative sources. We focus especially on the issues of development of local research capacity in terms of ownership of research purposes and processes, and expansion of the intellectual economy. As explained by the United Nations (2010), we acknowledge the tensions inherent in the terminology used to distinguish countries with different states of economic development (e.g., Western/emerging, high income/low income, developed/developing, Global North/Global South). In this paper, we carefully and hesitantly use the terms "developed countries" and "developing countries" to refer to only one aspect of a country's culture. We also cautiously use the term "non-mainstream communities" to refer to communities regarded as outside of the dominant society (such as Aboriginal communities in Canada). We ascribe to Maclure's (2006) distinction between endogenous research as "donor-controlled inquiries" versus more praxis-oriented research. We are also concerned about enabling the voices and work of less heard scholars into the global research community.

To these ends, we first describe the scope and nature of literacy projects funded by organizations outside of standard governmental agencies. The funding organizations that we investigated were those that were made known to Canadian literacy researchers in one Faculty of Education and do not constitute all possible alternative funding sources available to Canadian scholars. Following this description of funding organizations and their literacy projects, we draw 
from a review of the critical literature of alternatively funded educational research to identify the tensions and dilemmas that can arise when scholars from developed countries and such funders form relationships to undertake literacy research in developing countries. We conclude the article by turning to examples of current Canadian literacy research carried out in developing countries. These examples are not necessarily funded by alternative sources, but illustrate application of Tri-Council policy and provide guidance in designing, conducting, and disseminating locallyempowering and globally-connected literacy research. Our examples of current research do not represent the entire body of this focus of Canadian literacy research but are drawn from the authors' personal interactions with colleagues who conducted the research. Through these processes, we hope to extend the conversation among Canadian literacy researchers which might assist in the formation of guidelines for participation in research in developing countries, particularly research funded by alternative sources to traditional academic funding.

\section{Scope and Nature of Literacy Projects Funded by Alternative Sources}

In consultation with a Faculty of Education Research Grant Facilitator, international, governmental, and NGOs that provided competitive funding to faculty at the University of British Columbia during the 2009 academic year, were identified $(n=14)$. Data about funded projects in literacy were obtained through the organizations' websites and/or by direct contact with the organizations. The projects identified were not necessarily led by Canadian researchers. Table 1 lists the organizations that were surveyed and the primary location in which their projects were carried out (in North America or in developing countries). 
Table 1

Alternative Organizations Surveyed for Funding of Literacy Research and Primary Location of Research Projects Funded

\begin{tabular}{|c|c|c|}
\hline Organization & (North America) & Developing Countries \\
\hline Human Resources and Skills Development Canada & yes & \\
\hline RGK Foundation & yes & \\
\hline International Reading Association & yes & some \\
\hline WK Kellogg Foundation & yes & \\
\hline Spencer Foundation & yes & \\
\hline Canadian Council on Learning & yes & \\
\hline Canadian Language and Literacy Researchers Netw & yes & \\
\hline Carnegie Corporation & yes & some \\
\hline Canadian International Development Agency (CID & & yes \\
\hline Ford Foundation & & yes \\
\hline African Development Bank & & yes \\
\hline NAFSA: Association of International Educators & & yes \\
\hline Rotary Foundation & & yes \\
\hline John D. \& Catherine T. MacArthur Foundation & yes & yes \\
\hline
\end{tabular}

We also wanted to determine which aspects of literacy (e.g., family literacy, adult literacy, ESL) were funded by these alternative sources. Using Atlas-Ti, data from 627 projects that were funded across all 14 organizations were coded for research focus. Although researchers' names and affiliations were not always identified by the funders, those that were showed that these projects were predominantly carried out by US researchers. Several of the funders we identified have sponsored large numbers and diverse foci of literacy research over varying periods of time. As seen in Table 2, 11 major topics were identified. 
Table 2

Summary of Literacy Projects by Topics Funded by Alternative Organizations

\begin{tabular}{|l|c|c|}
\hline Topic/Literacy Research Focus & Total & Corresponding Theme \\
(Hautecoeur, 1997)
\end{tabular}

Note: $\mathrm{LI}=$ Literacies intervention; $\mathrm{TS}=$ Trouble spots; $\mathrm{P}=$ Partnership;

$\mathrm{P} \& \mathrm{~S}=$ Professionalization and standardization

Appendix 1 provides definitions of the topics. The research topics correspond to the themes of international literacy meetings identified by Hautecoeur (1997): (a) the professionalization and standardization of services and the quality criteria measurement of returns and certification (one topic or 102 projects); (b) partnership and collaboration among numerous actors in the public and private community and research sectors (one topic or 14 projects); (c) wide areas of literacies intervention: the workplace, new technologies, family and intergenerational literacy (five topics or 301 projects); and (d) "trouble spots": women and equity, research and criticism, multiculturalism and socio-demographic factors (two topics or 38 projects). Lastly, similar to the conclusions of Wickens and Sandlin (2007) and Choudry (2007), 
most projects focused on functional literacy rather than literacies that encourage critical reading and thinking.

Figure 1 shows the comparison of the main foci of literacy projects between North American-centered funders and funders targeting developing countries.

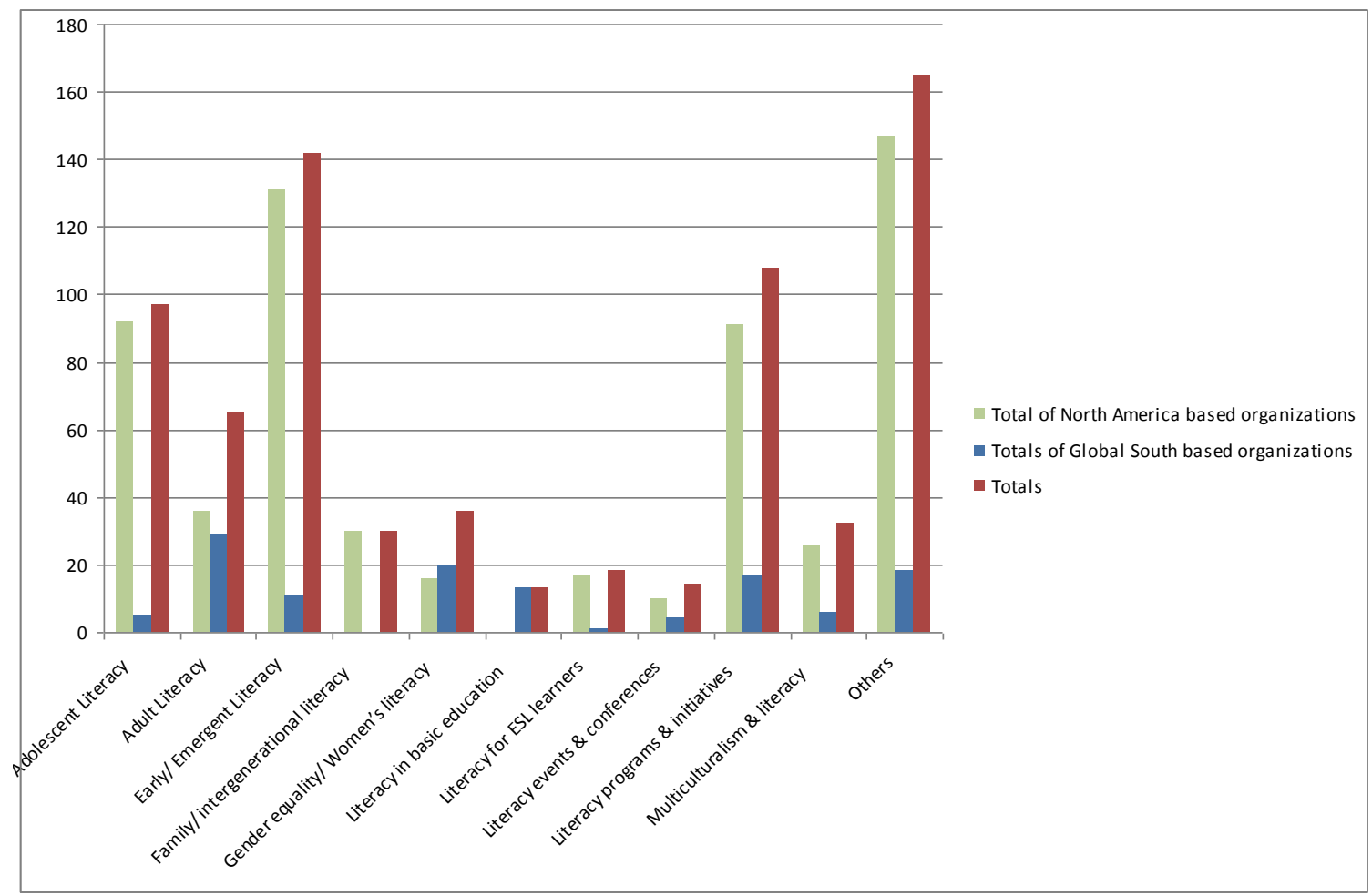

Figure 1. Comparison of literacy topics by funding source (N. America- or developing countrycentered).

In contrast to projects carried out in developing countries, projects in North America were more focused on the following topics: adolescent literacy, early literacy, family literacy, ESL, multiculturalism, and literacy programs (including interventions and other related literacy programs). The number of projects focused on adult literacy, gender equality/women's literacy, and literacy in basic education were nearly equal between both groups of organizations (those primarily that funded projects in North America and those that primarily funded projects in developing countries). Hamilton and Hillier (2007) argue that the topics and themes of funded research are shaped by ideologies of literacy policy. In the case of literacy research in developing countries, the larger literacy policy discourses such as those of UNESCO, OECD, and the World Bank influence which projects organizations select to fund. Consequently, what is researched is often imposed rather than locally derived.

Due to limitations of our data, including identifying alternative funding sources made known to only one Canadian institution and difficulties in identifying the complete scope of 
funded projects for each organization, we present these findings as trends rather than accurate comparisons between funders of North American and international literacy projects.

\section{Tensions and Dilemmas: Relationships between the Academy and Alternative Funding Organizations}

Searches were conducted in ERIC, EBSCO, Education Index and Psyc Info using the key words organizations (including non-profit organizations, agencies, foundations, non-government organizations, etc.), researchers, academics, funding, research bias, power, and literacy research. Twenty publications were reviewed, and together represent critical perspectives on the issues of alternatively-funded educational research, including literacy research, conducted in developing countries (predominantly African countries) and in marginalized communities (e.g., Canadian and Australian indigenous communities). Three of the articles were written by Canadian researchers in areas of education other than literacy, and two were co-authored with Western and African researchers. The following section summarizes this literature.

\section{Power Imbalances and Ideological Influences}

Establishing a praxis-oriented endogenous research culture in developing countries is influenced by the practices and expectations of agencies of alternative funding and by the unique political, financial and ideological contexts of research in Africa (Archer, 2004; Buchert, 1998; Freeman \& Faure, 2003; Fuhriman, Ballif-Spanvill, Ward, Solomon \& Widdison-Jones, 2006; Hayman, 2007; Higgins \& Rwanyange, 2005; Limage, 2007; Maclure, 1997; Mignolo, 2000; Samoff, 1999). The current Tri-Council policy recognizes that the second influence-political, financial and ideological contexts - must be dealt with by Canadian researchers working in international and Aboriginal contexts. Thus we acknowledge that these challenges are common to researchers regardless of funding source. However, the specific relationships between local institutions and funding organizations working in the country can further complicate relationships and arrangements between outside researchers and the local community where research is to be conducted.

Two themes that emerged from the literature were: a) power imbalances between key players (e.g., funders, researchers, local government, research participants); and b) political and ideological influences on alternatively-funded literacy research. As seen in Figure 2, these themes can be represented as three nested relationships-relationships between those most directly affected, relationships between institutions, and relationships among worldviews or ideologies. The literature we reviewed revealed that these relationships may be differently scaled particularly when research involves donor-based funding. 


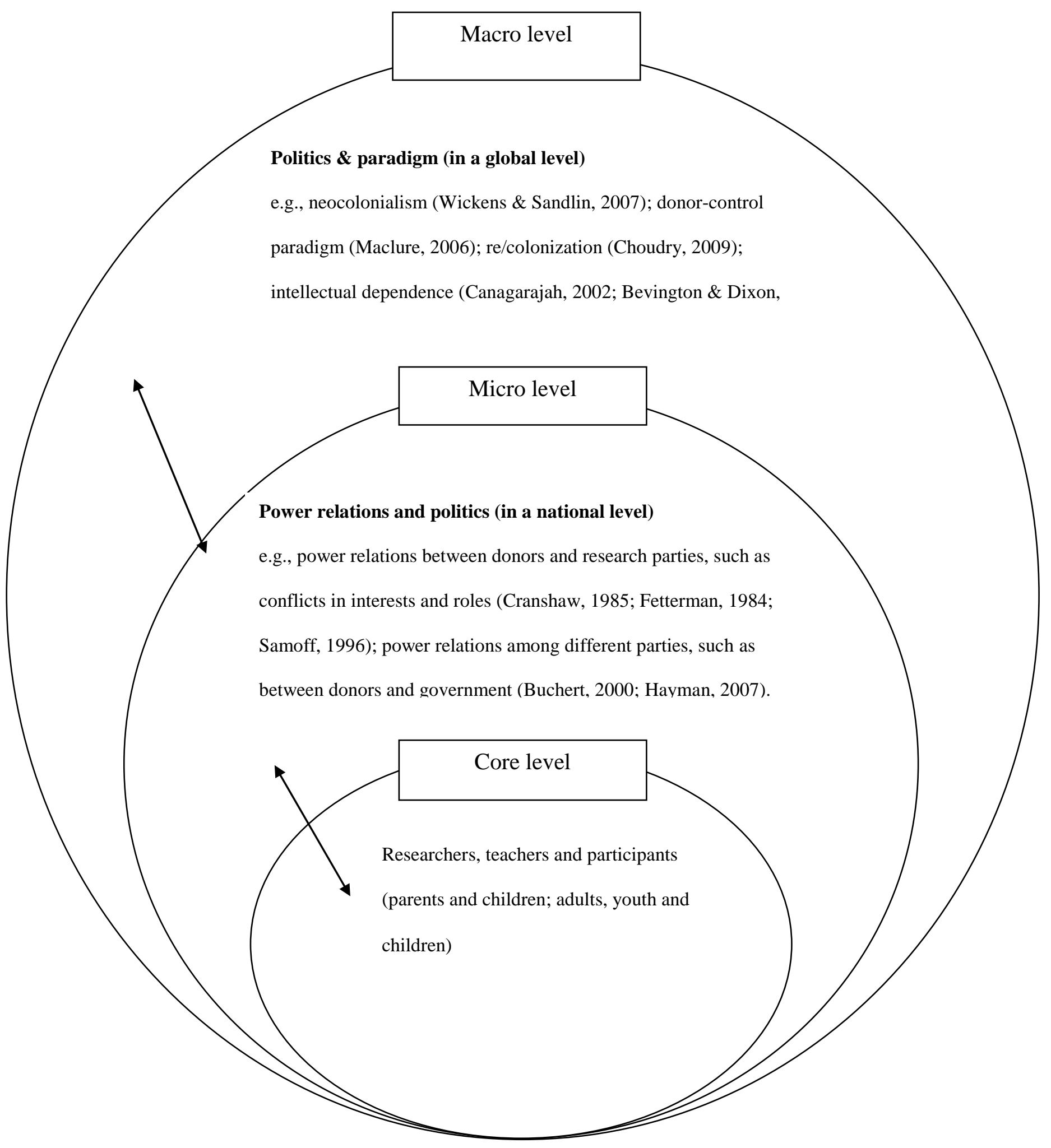

Figure 2. Levels of relationships in alternatively-funded literacy research (international aid, governmental, and NGOs). 
Briefly, at the core level are people who are directly involved in the research including researchers, educators, and participants and their families. Power imbalances can compromise trust and respect that should undergird these personal and professional relationships. At the institutional level, outside funders may have to negotiate (openly or covertly) with the political elite of the local country (including ministries of education) as these bodies often have the authority to determine what research is permitted and how it will be used. Ultimately, as discussed above about the agenda-setting power of literacy policies, the overarching ideologies of all those involved in the research, at the local and global levels, will shape all stages of the research. It is at this level that the need for critical consciousness is most acute in order for research to effect social change and the de-linking of developing countries' academic dependence on others' research paradigms. The following provides additional points about these factors of alternatively-funded research in developing countries.

\section{Personal and professional relationships.}

In developing countries where alternatively-funded research is being conducted, there is typically little opportunity for local scholars to actively participate in this research (Buchert, 1998; Cranshaw, 1985; Samoff, 1996, 1999). Universities are poorly resourced to support research and faculty members are under pressure to teach large numbers of students. Inventories and analyses of 300 UNESCO-funded educational studies in Africa from 1989-1995 revealed that the majority of these studies were initiated and conducted by external agencies using external "experts" to establish the frameworks, and that African scholars were employed to do tasks defined by the "experts" (Buchert, 1998, p. 358). Roles of local scholars and researchers are usually restricted to part-time employees of funding agencies and these people are selected for their fit with Western training (Cranshaw, 1985). Furthermore, research participants are more often "studied" than meaningfully engaged in the research process, which, along with the marginal role of African scholars, works against building local ownership of literacy issues and initiatives. This concern is taken up in the Tri-Council policy in the section on Aboriginal research, and recommendations are made for designing collaborative research affecting all stages and aspects of the research, using participatory methods, and "support(ing) capacity building through enhancement of the skills of community personnel in research methods, project management, and ethical review and oversight" (p. 125). We propose that these guidelines can be extended to conducting research in developing countries.

\section{Institutional/National relationships.}

Not atypically, budgets for research and education in developing countries are determined by those in elite government positions who help shape agendas, including the type of research carried out and policy implications, to fit their own ideologies. We also recognize the greater influence of global ideologies on research agendas beyond the agendas of any local elite governments, in different degrees in all contexts. Buchert (1998) discusses the complex and intricate relationship of research to policy making that is caused by dependency on international or outside expertise as well as by weak links between local researchers and policy makers, and the weak diagnostic capabilities of ministries of education (p. 354). Samoff (1996) describes the "mystification of knowledge and power relationships" by those constituting the "financialintellectual complex." Those who have access to research (knowledge) continue to obtain funding and influence. Within the financial-intellectual complex, accountability to external 
agencies/funders and to the broader international community that demands evidence of progress to such global goals as Education for All (World Bank, 2009) also undermines any progress in local ownership of education (Higgins \& Rwanyange, 2005). In this way, research may serve the interests of foreign funding groups (donors) who may be in alliance with the core elite (Hayman, 2007; Maclure, 2006). This situation also contributes to external dependency when hierarchical rather than collaborative relations are created between institutions and scholars.

As identified in our review of the literature, findings from outcomes-based research, the predominant research design in donor-funded projects in developing countries, are often used as the basis for policy and educational reform. Maclure (2006) argues that this type of research produces measurable results but limited depth of study of local literacy practices beyond "schooled colonialist" conceptions. Further, theoretical frameworks of these donor-funded projects are limited to positivist perspectives that can produce desired quantitative results. When local policy makers' favor designing implications from this "Western" research, neocolonialism is perpetuated (Choudry, 2007; Maclure, 2006; Wickens \& Sandlin, 2007). The Canadian TriCouncil policy states that research must be relevant and beneficial to the community being studied. Adhering to this principle, along with the use of collaborative research processes and participatory methods mentioned above, would enable consideration of research designs that would yield deeper and richer understandings of local literacies and consequently better inform literacy education.

\section{Ideology level.}

As explained above, research paradigm privileging (scientific method) and the perpetuation of neocolonialism or re/colonization restrict the kind of research leading to social change (Choudry, 2007; Fuhriman et al., 2006; Wickens \& Sandlin, 2007). As well, perceptions of local research and researchers as intellectually substandard compared to the more widely published researchers and globally accessible research of developed countries are perpetuated with this adherence to one "best" paradigm. Although a robust body of local research can be found in sub-Saharan African countries, it remains unpublished and overlooked by local policy makers due largely to the distance from what is often interpreted by local researchers as the gold standard of Western-produced research (Maclure, 1997, 2006). This research is also left out of the Western corpus because of different social conventions in academic publishing (Canagarajah, 2002). A challenge to this is the recently formed African Journals Online (http://ajol.info/) that promises more opportunity for knowledge access both within and outside Africa. Articles from the hundreds of journals in this resource are available for free to scholars from developing countries and for a fee to those from "high income" countries. These external and internal conditions suggest that, "educational research has been dislocated from national contexts and has become largely the prerogative of researchers and institutions situated in North America and Europe" (Maclure, 2006, p. 82). This makes it immensely complex and difficult to develop an endogenous research culture in African countries that is financially and intellectually independent of developed countries (Bevington \& Dixon, 2005; Hautecoeur, 1997; Maclure, 2006; Mingolo, 2000; Smith, 1999).

One successful model of addressing this challenge has been the establishment of education research networks by African scholars in various regions: Eastern and Southern Africa (ERNESA), West and Central Africa (ERNWACA), and across Africa as the Association for the Development of Education in Africa (ADEA). The two regional groups were created to "increase 
research capacity, strengthen collaboration among researchers and practitioners, and promote African expertise on education so as to positively impact educational practices and policies" (The Educational Research Network for West and Central Africa, 2011, n.p.). ADEA's vision is to "become a leader in the processes of dialogue, sharing and learning for the qualitative transformation of education in support of Africa's development" (ADEA, 2009, n.p.). However, ADEA is financed largely by donor agencies and thus these agencies are heavily represented in the governance along with ministers of education.

We suggest that the constraints and challenges of establishing ownership of research that are faced in African countries are similar in all developing countries and in marginalized communities anywhere, including Aboriginal communities in Canada, and those in Canadian inner cities and remote and isolated locations. As mentioned above, the current Tri-Council policy provides guidance in ways of responding to these challenges to strengthen local ownership of research at all stages. We argue that this guidance is particularly relevant to the more pronounced and unique challenges inherent in research funded by alternative sources. The models of research networks of African scholars and ministers described above also lead the way forward.

\section{Towards a Locally Empowering and Globally Connected Literacy Research Community: Directions from Canadian Researchers}

Recent work by some Canadian literacy researchers employs principles for ethical participation in and contribution to praxis-focused endogenous research, thereby supporting development of a richer, more diverse global intellectual network. As stated earlier, our examples are limited to the work of the authors' colleagues and most are funded by traditional sources. Rather than referring to specific projects or individual researchers, we identify some key principles underlying the growing work of those Canadian literacy scholars involved in research that is framed in social change in developing countries (examples cited at the beginning of this article). These principles accord with those of the Canadian Tri-Council policy; however, whereas the Tri-Council policy is geared broadly to the social and medical sciences, our examples provide specific contexts of literacy research. The principles we identify are: a) invest time to build trust and understanding; b) use culturally sensitive perspectives of literacy; c) use research methodologies capable of gaining insider perspectives and that foster inclusion of local researchers; and d) ensure respectful relationships and expectations among all participants.

Invest time to build trust and understanding.

Laying the groundwork for new research relationships and contexts requires increased attention to issues of mutual respect, cultural awareness and sensitivity, and the need to listen and to engage in meaningful conversations with potential research partners. Although some might argue that these issues are not part of the research process, reconnaissance and reflection are critical to conducting any further inquiries, and should become an explicit part of the research process (Asselin \& Doiron, 2009). This is recognized in the Tri-Council guidelines as engagement with the community that is the focus of research. This engagement includes "becom(ing) informed about, and to respect, the relevant customs and codes of research practice that apply in the particular community or communities affected by their research" (p. 117). The Canadian literacy researchers in our sample have invested significant personal time with the local communities, research partners, and community organizations preliminary to designing research and finding ways to not only learn for themselves but to incorporate local engagement 
at multiple levels. This process is not restricted to early stages of research but constitutes on ongoing reflective mindset. For example, in Kendrick and Jones' (2008) study of Ugandan adolescent girls' representations of literacy, one of the researchers had lived in the community for some time as a volunteer in several educational settings before the study began, and the two research assistants were also part of the community, one as a local teacher and the other as a longtime volunteer in a school. Similarly, Oates (2009) had spent extensive time in Kabul in previous projects, and had become colleagues with a member of the family that later became the focus of the case study. Her own role as co-researcher with the local case study family member enabled her to continue to monitor and build trust throughout the research process.

\section{Culturally sensitive perspectives of literacy.}

Our examples of Canadian literacy researchers working in developing countries ground their work in critical, multiple, and sociocultural perspectives of literacy. Literacy research in developing countries must be situated beyond autonomous views of literacy that can lead to confounding of access and abilities, and ignorance of local literacy forms and practices. Street and Lefstein (2007) argue that researchers should "suspend judgment as to what constitutes literacy among the people they are working with until they are able to understand what it means to the people themselves, and which social contexts reading and writing derive their meaning from" (p. 42). This attention to local understandings is endorsed in the Tri-Council policy: "Researchers should engage the community in identifying Elders or other recognized knowledge holders to participate in the design and execution of research, and the interpretation of findings in the context of cultural norms and traditional knowledge" (p. 126).

Related to this is a broadened view of literacy, past that of measurable skills to that of a literacy ecology (Barton, 1994). The studies in our sample are grounded in how literacy is embedded in social activities, as well as how it is constructed over time and space. Street (2003) argues for a hybridized view of local and global literacy practices, and posits this perspective as the heart of the New Literacy Studies. Drawing from this, a multiple literacies perspective looks at literacy practices beyond language and print to include visual, kinesthetic, spatial, etc. modes. Ultimately, the value of literacy as a means of economic development needs to extend beyond mere economic gains to a more holistic measure of quality of life. Literacy researchers focused on such matters as health and life goals are challenged to model this notion of literacy values while honoring the Tri-Council's (2010) directive that "research should benefit the participating community (e.g., training, local hiring, recognition of contributors, return of results), as well as extend the boundaries of knowledge" (p. 124). In this way, an expanded and local view of literacy is more aligned with Tri-Council policy than autonomous views of literacy.

\section{Research methods.}

Methodological shifts from positivist approaches to more interpretative methods are necessary to gain such ecological, situated, hybridized, and multiple views of literacy. Canadian literacy researchers in our sample use culturally sensitive research methods recommended in the literature (Anderson, 2009; Evans, Hole, Berg, Hutchinson, \& Sookraj, 2009; Thomas, 2008). Research instruments developed in other contexts are prone to ethnocentrism (Thomas, 2008) among other problems affecting validity and most importantly, use of results to enforce nonempowering educational policy and programs. Qualitative research methods, including participatory action research, case studies, and ethnography, can capture the particular local 
literacy practices and perspectives, and findings can be used to inform development of meaningful literacy education. Building on the rich foundational understandings of local literacies, new directions in educational policy research are possible For example, Tembe and Norton's (2008) investigation of local understandings of a recently implemented policy of first language instruction in Ugandan primary schools revealed the role of the community in actualizing the policy and provided clear direction for improving multilingual education. In these ways, some Canadian literacy researchers working in developing countries uphold the TriCouncil policy of conducting research that is relevant and beneficial to the community and to the broader literature of literacy.

Some Canadian researchers are expanding research populations to include participants in both developed and developing countries. For example, in one study, students in two African countries and in Canada are connected through global learning networks around a common literacy pursuit (Kendrick, Early \& Norton, 2009). This virtual connection between communities also allows the researchers to study the reshaping of literacy practices and forms when local literacies move to global contexts. A variation of this type of cross-cultural study is the use of a symmetrical design so that the same research is being conducted in both Canada and in a developing country around problems that are equally urgent but in different contexts such as young people's conceptions of digital literacy and preparing teachers to teach in multilingual classrooms (Asselin et al., submitted, 2011). In this approach, researchers in both countries coconstructed the research questions and methodology. Respectful acknowledgement of multimodality as a form of literacy/representation is another practice in our sample of Canadian literacy research. Drawings, dramatizations, and photographs by the research participants enable insights about literacy concepts and practices that differ from those gained only by linguistic means (e.g., Kendrick \& Jones, 2008; Mutonyi \& Kendrick, in press). For example, giving children digital cameras to record their own perceptions of language and literacy not only signals respect for the child as research participant but increases data validity because the child has direct control over what is selected to represent his/her perceptions. Additionally, images from the digital cameras provide the research collaborators with a commonly accessible form of data that can prompt discussion between participants and the researchers, and between the researchers about underlying assumptions of such core concepts as literacy, learning, and knowledge.

\section{Ethical guidelines.}

Of paramount concern are the ethical responsibilities of conducting research in international contexts where power relations between the researchers and participants, and between local and foreign researchers, can be misused, intentionally or unintentionally. As stressed in the Tri-Council policy, relationships with participants are particularly critical when working with vulnerable populations and efforts must be made to include these people in the research (p. 116). Ethical challenges must be anticipated including dealing with information that reveals a child's abusive situation and dealing with participants' sole expectations of the research as tangible benefits for the community. Similar to the Tri-Council's basic principles of human dignity, a widely accepted ethical framework (Schenk \& Williamson, 2005) that addresses this power imbalance and the possibility of exploitation is based on three fundamental duties of the investigator: respect for persons, beneficence, and justice. These principles should hold throughout every stage of research. As Morrow (2009) explains: "attention to research ethics is not a one-off, tick-box activity, but is an ongoing process that relates to the interactions between 
researchers and research respondents and beyond, to analysis of data and dissemination of findings" (p. 1). Some examples from our sample of Canadian literacy researchers are: a) developing collaborative relationships with local educators and researchers to involve codesigning, conducting, and authoring (Asselin et al., submitted; Mutonyi \& Kendrick, in press; Oates, 2009; Rogers, Conteh, \& Moanakwena, 2009; Tembe \& Norton, 2008); b) developing rapport with the local community and research participants, being especially attentive to those who may be vulnerable due to gender, age, social status, or health (Kendrick \& Jones, 2008; Norton \& Mutonyi, 2010; Oates, 2009); and c) supporting development of open access platforms for publication of locally-based research beyond national borders (Metcalfe, Esseh, \& Willinsky, 2009).

How these ethical principles actually play out in alternatively-funded, and particularly donor-controlled, research is what we argue needs urgent attention from Canadian literacy scholars working in developing countries. We recognize the power relations inherent in donorcontrolled research especially and that donors and their organizations often have ideologies (or findings) that they want validated. These organizations need to be educated about the TriCouncil policies, particularly those articles and directives concerning building trust, using qualitative and participatory approaches to research, and designing research that is beneficial both to the community being researched and the disciplinary literature. They also need to be educated about conceptions of literacy beyond autonomous models and measurable skills to those of sociocultural, critical and multiple literacies. Finally, there needs to be frank discussion about the ways that research can move from being the prerogative of "others" to ways of enabling others' active presence in the global knowledge economy.

\section{Conclusion}

Whether at home or in others' contexts, ethical responsibilities for conducting research are increasingly scrutinized. This is more so in international contexts where power relations between the researchers and participants, and between local and foreign researchers, can be misused, intentionally or unintentionally. The challenges that researchers face in these endeavors are particularly acute and complex when projects are funded by the types of alternative sources identified in this article. Given the historical absence of critical review and peer scrutiny of the financial-intellectual complex (Samoff, 1996), we argue that Canadian literacy researchers need to be aware that control of the research process by such alternative funding organizations will likely continue to some degree. Canadian literacy researchers working in developing countries apply sanctioned ethical guidelines for enabling the development of research that empowers local communities and a new intellectual economy. Building such a literacy research culture includes a shift from favored positivist designs; employment of a praxis approach; use of sociocultural and sociopolitical frameworks; improved dissemination now afforded by the internet; training and networking of local scholars; communication between local scholars and policy makers; and strengthening the role of local universities as research institutions. Achieving such a culture is the challenge for literacy researchers in both developing and developed countries. This goal also applies to literacy research within marginalized communities where researchers must approach any prospective research community cognizant of the same tensions and dilemmas. Within this new theoretical, ideological, and political landscape of literacy research, Canadian literacy researchers refer to the current Tri-Council policy, which recognizes special considerations for working in developing countries and in international and Aboriginal communities. Alongside this 
reference to Tri-Council policy, Canadian literacy researchers can begin to articulate specific roles and activities in building local research cultures in these communities that reveal local, global, multiple, and local literacies; that guide development of educational policy and curriculum based on this research; that are intended to redress the observed inequities and support development of imagined communities; and that facilitate the extension of the dominant intellectual economy to those that are currently less visible and less heard.

\section{References}

Anderson, W. (2009). From subjugated knowledge to conjugated subjects: Science and globalisation, or postcolonial studies of science? Postcolonial Studies, 12(4), 389-400. doi: 10.1080/13688790903350641

Archer, D. (2004). NGO perspectives on adult literacy. Convergence, 37(3), 65-74.

Asselin, M., Dobson, T., Filipenko, M., Getnet, Z., Teferra, T., \& Williams, G. (submitted, 2011). Researching multiple languages and literacies in Ethiopia and Canada: A model for collaborative research. Proposal submitted to the Pan African Reading Conference, Botswana, July 11-14, 2011.

Asselin, M., \& Doiron, R. (2009). Reconnaissance and reflection: Foundations for collaborative international research with Canada and Ethiopia. Proceedings of the 2009 Research Forum of the International Association of School Librarianship, Padua, Italy.

Association for the Development of Education in Africa. (2009). Retrieved from http://www.adeanet.org/adeaPortal/

Barton, D. (1994). Literacy: An introduction to the ecology of written language. Oxford, UK: Blackwell.

Bevington, D., \& Dixon, C. (2005). Movement-relevant theory: Rethinking social movement scholarship and activism. Social Movement Studies, 4(3), 185-208. doi: $10.1080 / 14742830500329838$

Buchert, L. (1998). Education sector analysis in Africa: An evolving case in mutual north-south learning. Prospects, 28(3), 353-363. doi: 10.1007/BF02736810

Canadian Institutes of Health Research, Natural Sciences and Engineering Research Council of Canada, and Social Sciences and Humanities Research Council of Canada. (2010). Retrieved from http://www.pre.ethics.gc.ca/pdf/eng/tcps2/TCPS_2_FINAL_Web.pdf

Canagarajah, A. S. (2002). A geopolitics of academic writing. Pittsburgh: University of Pittsburgh Press.

Choudry, A. (2007). Learning in social action: Knowledge production in social movements. McGill Journal of Education, 44(1), 5-17.

Cranshaw, B. (1985). Contract research, the university, and the academic. Higher Education, 14, $665-682$.

Evans, M., Hole, R., Berg, L. D., Hutchinson, P., \& Sookraj, D. (2009). Common insights, differing methodologies: Toward a fusion of indigenous methodologies, participatory action research, and white studies in an urban aboriginal research agenda. Qualitative Inquiry, 15(5), 893-910. doi:10.1177/1077800409333392

Fetterman, D. M. (1984). The art of moral decision making in educational research. Paper presented at the Annual Meeting of the American Educational Research Association, Orleans, LA. 
Freeman, T., \& Faure, S. (2003). Local solutions to global challenges: Toward effective partnership in basic education. Final report. The Hague: Netherlands Ministry of Foreign Affairs for the Consultative Group of Evaluation Departments. Retrieved from UNICEF website: http://www.unicef.org/evaldatabase/index_29684.html

Fuhriman, A., Ballif-Spanvill, B., Ward, C., Solomon, Y., \& Widdison-Jones, K. (2006). Meaningful learning? Gendered experiences with an NGO-sponsored literacy program in rural Mali. Ethnography and Education, 1(1), 103-124. doi: $10.1080 / 17457820500512887$

Hamilton, M., \& Hillier, Y. (2007). Deliberative policy analysis: Adult literacy assessment and the politics of change. Journal of Educational Policy, 22(5), 573-59.

Hautecoeur, J. (1997). A political review of international literacy meetings in industrialized countries, 1981-1994. International Review of Education, 43(2/3), 135-158.

Hayman, R. (2007). Are the MDGs enough? Donor perspectives and recipient visions of education and poverty reduction in Rwanda. International Journal of Education Development, 27(4), 371-382. doi.org/10.1016/j.ijedudev.2006.10.002

Higgins, L., \& Rwanyange, R. (2005). Ownership in the education reforms process in Uganda. Compare, 35(1), 7-26. doi: 10.1080/03057920500033464

Kendrick, M., Early, M., \& Norton, B. (2009). Literacy, multimodality and imagined communities: Connecting English language learners through global learning networks. SSHRC Standard Research Grant. Retrieved from http://lled.educ.ubc.ca/sites/lled.educ.ubc.ca/files/pdf/kendrick.pdf

Kendrick, M., \& Hissani, H. (2007). Letters, imagined communities, and literate identities. Journal of Literacy Research, 39(2), 195-216. doi: 10.1080/10862960701331944

Kendrick, M., \& Jones, S. (2008). Girls' visual representations of literacy in a rural Ugandan community. Canadian Journal of Education, 31(2), 371-403. Retrieved from http://www.csse.ca/CJE/Articles/FullText/CJE31-2/CJE31-2-kendrick\&jones.pdf.

Limage, L. J. (2007). Organizational challenges to international cooperation for literacy in UNESCO. Comparative Education, 43(3), 451-468. doi: 10.1080/03050060701556471

Luke, A. (2003). Literacy the other: A sociological approach to literacy research and policy in multilingual societies. Reading Research Quarterly, 38(1), 132-141.

Maclure, R. (1997). Overlooked and undervalued: A synthesis of ERNWACA reviews on the state of educational research in West and Central Africa. Washington, DC: Academy of Educational Development. Retrieved from http://sara.aed.org/publications/education/overlook/overlook.pdf

Maclure, R. (2006). No longer overlooked and undervalued? The evolving dynamics of endogenous education research in sub-Saharan Africa. Harvard Educational Review, 76(1), 80-109.

Metcalfe, A., Esseh, S. S., \& Willinsky, J. (2009). International development and research capacities: Increasing access to African scholarly publishing. Canadian Journal of Higher Education, 39(3), 89-109.

Mignolo, W. D. (2000). Local histories, global designs: Coloniality, subaltern knowledges and border thinking. Princeton, NJ: Princeton University Press.

Mitchell, C. Moletsane, R., Stuart, J., Buthelezi, T., \& de Lange N. (2008). Taking the picture, changing the picture. Visual methodologies in educational research in South Africa. 
South African Journal of Educational Research, 28(3), 365-383. Retrieved from: http://www.ivmproject.ca/images/photo_voice/CHILDRENFIRSTARTICLE.pdf

Morrow, V. (2009). The ethics of social research with children and families in Young Lives: Practical experiences. Young Lives Working Paper 53. Retrieved from http://www.younglives.org.uk/publications/working-papers/wp-summaries/summaryworking-paper-53.

Mutonyi, H., \& Kendrick, M. (in press). Cartoon drawing as a means of accessing what students know about HIV/AIDS: A case study in Uganda. Visual Communication Journal.

Norton, B., \& Mutonyi, H. (2010). Languaging for life: African students talk back to HIV/AIDS research. Language Policy, 9(1), 45-63.

Oates, L. (2009). Literacy in an extended family household in Kabul: A case study. Language and Literacy, 11(1). Retrieved from http://www.langandlit.ualberta.ca/Spring2009/ Oates.pdf

Rogers, T., Conteh, B., \& Moanakwena, P. (2009). Digital literacies among Botswana youth at risk: Documenting community life and imagining social futures. 6th Pan African Reading For All Conference, Dar Es Salaam Tanzania, Reading For All/Pan African Voice for Literacy. Retrieved from http://www.renafrica.org/Oct09HTML/October09.html\#south

Samoff, J. (1996). African education and development: Crisis, triumphalism, research, loss of vision. Alberta Journal of Educational Research, 42(2), 121-147.

Samoff, J. (1999). Education sector analysis in Africa: Limited national control and even less national ownership. International Journal of Educational Development, 19(4/5), 249272. doi:10.1016/S0738-0593(99)00028-0

Schenk, K., \& Williamson, J. (2005). Ethical approaches to gathering information from children and adolescents in international settings: Guidelines and resources. Washington DC: $\begin{array}{llll}\text { Population } & \text { Council. } & \text { Retrieved }\end{array}$ http://www.popcouncil.org/pdfs/horizons/childrenethics.pdf

Smith, L. T. (1999). Decolonising methodologies: Research and indigenous peoples. Dunedin: University of Otago Press and London: Zed Books.

Street, B. (2003). What's 'new' in the New Literacy Studies? Critical approaches to literacy in theory and practice. Current Issues in Comparative Education, 5(2), 77-91.

Street, B., \& Lefstein, A. (2007). Literacy: An advanced resource book. New York: Routledge.

Tembe, J., \& Norton, B. (2008). Promoting local languages in Ugandan primary schools: The community as stakeholder. Canadian Modern Language Review, 65(1), 33-60.

The Educational Research Network for West and Central Africa. (2011). Retrieved from http://www.ernwaca.org/web/spip.php?rubrique2

Thomas, A. (2008). Focus groups in qualitative research: Culturally sensitive methodology for the Arabian Gulf? International Journal of Research and Method in Education, 31(1), 77-88. doi: 10.1080/17437270801919941

United Nations. (2010). Standard country or area codes for statistical use. Retrieved from http://unstats.un.org/unsd/methods/m49/m49.htm

Wickens, C. M., \& Sandlin, J. A. (2007). Literacy for what? Literacy for whom? The politics of literacy education and neocolonialism in UNESCO- and World Bank-Sponsored literacy programs. Adult Education Quarterly, 57(4), 275-292. 
World Bank. (2009). Education for All. Retrieved from: http://web.worldbank.org/WBSITE/ EXTERNAL/TOPICS/EXTEDUCATION/0,,contentMDK:20374062 menuPK:540090 pagePK:148956 piPK:216618 theSitePK:282386,00.html

\section{Author Biography}

Marlene Asselin is Associate Professor in the Department of Language and Literacy Education at the University of British Columbia. She coordinates the teacher librarian program and language and literacy education component of the elementary teacher education program. She has research programs in new literacies and social media, information literacy, and teacher education and literacy education in Ethiopia.

Ray Doiron is Professor in the Faculty of Education at the University of Prince Edward Island. He teaches courses in early literacy and school librarianship. His research interests include digital literacies, social networking and school libraries and he currently has research projects on play in early childhood education.

Jon Shapiro is currently Senior Associate Dean of the Faculty of Education and Professor of Literacy Education and at the University of British Columbia. His research interests are in the areas of emergent literacy, affective dimensions of reading particularly for boys, and international literacy development projects. 


\section{Appendix}

Brief Descriptions and Examples of Categories Used to Identify Main Foci of Literacy Projects funded by Organizations

\section{Adolescent Literacy:}

Codes that include various topics from literacy programs to teacher training and literacy materials for adolescents and youth.

e.g., Adolescent literacy improvement; Summer literacy-based curriculum- youth; Young people's visual literacy and media literacy; Youth news including literacy skills, community engagement, teacher training program, adolescent literacy instruction, curriculum materials, and standards for middle and high school literacy coaches

Adult Literacy:

Codes that include various topics from literacy programs to teacher training and literacy materials for adults.

e.g., Promoting literacy skills- rural women and youth; Employment training and literacy program for women- poor families' quality of life; Adult literacy- health; Economic development and functional literacy for women

Early/Emergent Literacy:

Codes that include various topics from literacy programs to teacher training and literacy materials for young children and elementary school children.

e.g., Early literacy projects; Early literacy intervention programs; Early literacy programs; Early literacy and library; Children literacy programs; Summer literacy programs; Early literacyevaluation of TV series; Early literacy- public TV series; Teacher preparation- pre-K to 4th grade literacy teachers; Teacher preparation- pre-service teachers- secondary school literacy; Teacher preparation for pre-service teachers and adolescents reading and writing

Family/Intergenerational Literacy:

Codes that include various topics from literacy programs to literacy materials for diverse types of families.

e.g., Distance-learning radio program for improving levels of rural family literacy and teacher training; Family literacy and early literacy; Library access; Family literacy (the ready to learn family literacy initiative); Literacy program- low income families

Gender Equality/Women's Literacy:

Codes that include various topics from literacy programs to evaluation of literacy programs for women and girls.

e.g., Employment training and literacy program for women- poor families' quality of life; Literacy programs such as development and evaluation of functional literacy programs, women, street girls, young girls and women, programs including basic literacy and math skills, Health and quality of life of rural communities focused on women and girls and establishing literacy circles 
Literacy in Basic Education:

Codes that include various topics about literacy programs combined with basic education. e.g., Adult basic education and training planning group- attending international literacy forum; Basic education and gender equality- Afghan women community; Basic education in literacy and other areas; Basic education and gender equality

Literacy for ESL Learners:

Codes that include topics from literacy programs to teacher training and literacy materials for ESL (English as Second Language) learners and English learners.

e.g., Improvement of literacy skills for various groups: Latino English learners, academic literacy, secondary ESL learners, academic literacy skills, ESL learners

Literacy Events \& Conferences:

Campaign for child care and preschool educators; Importance of early childhood literacy conference; Community-based literacy programs; Literacy conference literacy conference- media literacy.

Literacy Programs \& Initiatives:

Codes that include various literacy programs and initiatives from local scale to nation-wide. e.g., Literacy-based conflict resolution program; Literacy program- local development, national literacy initiative

\section{Multiculturalism \& Literacy:}

Codes that include topics about literacy programs and resources for diverse cultural groups, such as marginalized cultural groups, minority cultural groups, indigenous groups and multiculturalism.

e.g., Marginalized cultural groups- literacy; Indigenous literature for children; Multicultural and reading response; Linguistics repertoire- minority students- middle school, literacy practicesmarginalized adolescents; Literacy practices-vernacular culture; Literacy learning and social status

Others:

Codes that do not fit the above categories, such as codes that include literacy in a specific subject area (e.g., financial literacy, health literacy, political literacy, scientific literacy, intertextuality, dyslexia etc.) but do not provide specific target population of the literacy. e.g., Financial literacy; Economic literacy- skills training- local government and civil society leaders; Assessment of the problem of health literacy; Special education- education to prepare deaf and hearing teachers- for comprehensive literacy, political literacy- school-based civic education curricula; Scientific literacy- evaluating reports of current scientific research; Intertextuality 